\title{
Kinky Hair Disease. Biochemical, Histochemical, and Ultrastructural Studies
}

\author{
KIMIKO HARA, ATSUHIKO OOHIRA, HIROSHI NOGAMI, KAZUYOSHI WATANABE, AND \\ SYUJI MIYAZAKI \\ Departments of Pediatric Neurology (K. H., K.W., S. M.) and Orthopaedic Surgery (H. N.), Central Hospital and \\ Department of Embryology, Institute for Developmental Research (A. O.), Aichi Prefectural Colony, Kamiya-cho, \\ Kasugai, Aichi, Japan
}

\section{Summary}

The biosynthetic activities of protein and collagen from the patient of kinky hair disease, were reduced to 70 and $50 \%$, respectively, compared with control.

In tissue cultures, fast-green FCF staining coarse granules were found in the cytoplasm of skin fibroblasts from the patient.

Ultrastructurally, collagen fibrils by iliac cartilage biopsy were irregular in width. Ruthenium red staining granules, presumed to be proteoglycans in the cartilage matrix, were relatively small in size and few in number. Chondrocytes showed poor development of organelles and relatively small glycogen accumulation.

\section{Speculation}

The metabolic disorder of copper may play a role in the reduced biosynthetic of collagen. There is a possibility that fast-green FCF staining coarse granules in the cytoplasm of skin fibroblast, may be a precursor material of collagen. The appearance of huge collagen fibrils in the cartilage matrix may be related to the decreased number of proteoglycan granules which are considered to play a role in fiber formation.

Kinky hair disease, a disorder associated with peculiar hair, convulsion, psychomotor regression, growth retardation, and early death, was first described by Menkes et al. (8) in 1962. Danks et al. (3) have indicated that kinky hair disease was the result of a copper deficiency due to defective intestinal absorption. The absence of copper is known to lead directly to the inhibition of crosslinking in both collagen and elastin $(1,10)$. In order to define this disorder more precisely, this paper presents clinical, radiologic, ultrastructural, and biochemical findings of kinky hair disease in a case study.

\section{CASE AND METHODS}

The male infant was first seen at the age of 5 months with bronchopneumonia. He had generalized tonic-clonic convulsion. He was born after an eventful 39 wk of gestation and an uncomplicated delivery with a birth wt of $3000 \mathrm{~g}$. He was pudgy, pale, and lethargic. His hair was depigmented, lustreless, tangled, and stood on end. He was floppy and unable to lift up his head from prone position. The function of all cranial nerves was intact and brisk tendon reflexes were observed.

Since the age of 7 months, he had required gavage feeding. He gradually became hypertonic. Myoclonic seizures were occasionally observed. At the age of 18 months, kinky hairs were macroscopically observed. He had neither head control nor spontaneous movement with the exception of withdrawal response to pain. $\mathrm{He}$ remained severely retarded and never responded socially. Only the tip of several teeth erupted. Gingiva and nasal mucosa were hypertrophic. (Fig. 1) The patient died of bronchopneumonia when he was 3 yr old.

Biopsies of skin and iliac cartilage were performed for the purpose of biochemical, cytologic, and electron microscopical investigations at the age of $2 \mathrm{yr}$.

\section{BIOCHEMISTRY OF SKIN COLLAGEN}

The skin segments ( $37 \mathrm{mg}$ wet $\mathrm{wt}$ ) excised at biopsy were minced with a \#11 surgical blade in ice-cold medium 199 supplemented with $15 \%$ fetal calf serum, and then replaced in $12 \mathrm{ml}$ of the fresh medium. After two days of preincubation in a $\mathrm{CO}_{2}$ incubator at $37^{\circ} \mathrm{C}$, the tissue was transferred to $10 \mathrm{ml}$ of Eagle's MEM containing $1 \mathrm{mg}$ of $\beta$-aminopropionitril fumarate, $0.5 \mathrm{mg}$ of ascorbic acid, $15 \%$ fetal calf serum, and $10 \mu \mathrm{Ci}$ of $\left[{ }^{14} \mathrm{C}\right]$ proline and incubated for $27 \mathrm{hr}$. After labeling with $\left[{ }^{14} \mathrm{C}\right]$ proline, the medium was removed from the tissue by centrifugation at $3000 \times g$ for 10 min. The medium was dialyzed against $0.9 \% \mathrm{NaCl}$, and the retentate was referred to as $M E D I U M$ in Figure 2. The tissue was homogenized at $4^{\circ} \mathrm{C}$ in a Potter-Elvehjem glass homogenizer in a $5 \mathrm{ml}$ of $1 \mathrm{M} \mathrm{Nacl}-0.05 \mathrm{M}$ Tris- $\mathrm{HCl}, \mathrm{pH} 7.5$, containing $1 \mathrm{mg}$ of purified rat skin soluble collagen as a carrier. The homogenate was stirred overnight at $4^{\circ} \mathrm{C}$. After centrifugation at $20,000 \times g$ for $30 \mathrm{~min}$, the residue was reextracted in $5 \mathrm{ml}$ of the buffer. Both supernatants were combined and dialyzed against $1 \mathrm{M} \mathrm{NaCl}-0.02$ $\mathrm{M}$ Tris- $\mathrm{HCl}, \mathrm{pH} 7.5$, at $4^{\circ} \mathrm{C}$. The retentate was referred to as EXTRACT in Figure 2. The final residue was washed exhaustively with ice-cold water containing $4 \mathrm{mM}$ of unlabeled proline, and then digested with $1 \mathrm{mg}$ pronase in $5 \mathrm{mM}$ of $0.05 \mathrm{M}$ Tris- $\mathrm{HCl}, \mathrm{pH}$ 8 at $50^{\circ} \mathrm{C}$ overnight. The digest was referred to as $R E S I D U E$ in Figure 2 . Total radioactivity and the radioactivity of $\left[{ }^{14} \mathrm{C}\right]$ hydroxyproline in these fractions were measured by the method of Juva and Prockop (7). Control skin segments (46 mg wet wt) excised from an 11 -month-old boy were also analyzed by the same methods described above.

\section{HISTOCHEMISTRY OF CULTURED SKIN FIBROBLAST}

Pieces of excised skin were cultured in medium 199 supplemented with $15 \%$ fetal calf serum, penicillin (100 units $/ \mathrm{ml})$ and streptomycin $(100 \mu \mathrm{g} / \mathrm{ml})$ for 10 days. The cultures were exposed to an atmosphere of $5 \% \mathrm{CO}_{2}$ in the air at $37^{\circ} \mathrm{C}$. Skin fibroblasts were stained with alcian blue, PAS, or by Masson's trichrome method after fixation in cacodylate buffer ( $\mathrm{pH} 7.4) 3 \%$ glutaraldehyde solution at $4^{\circ} \mathrm{C}$.

\section{ULTRASTRUCTURE OF ILIAC CARTILAGE}

Biopsy specimens from the iliac cartilage were fixed in $3 \%$ glutaraldehyde in cacodylate buffer $\left(\mathrm{pH} \mathrm{7.4)}\right.$ at $4^{\circ} \mathrm{C}$ for $3 \mathrm{hr}$, postfixed in $2 \%$ osmium tetroxide in cacodylate buffer for $2 \mathrm{hr}$, dehydrated through series of ethanol and acetone, and embedded 


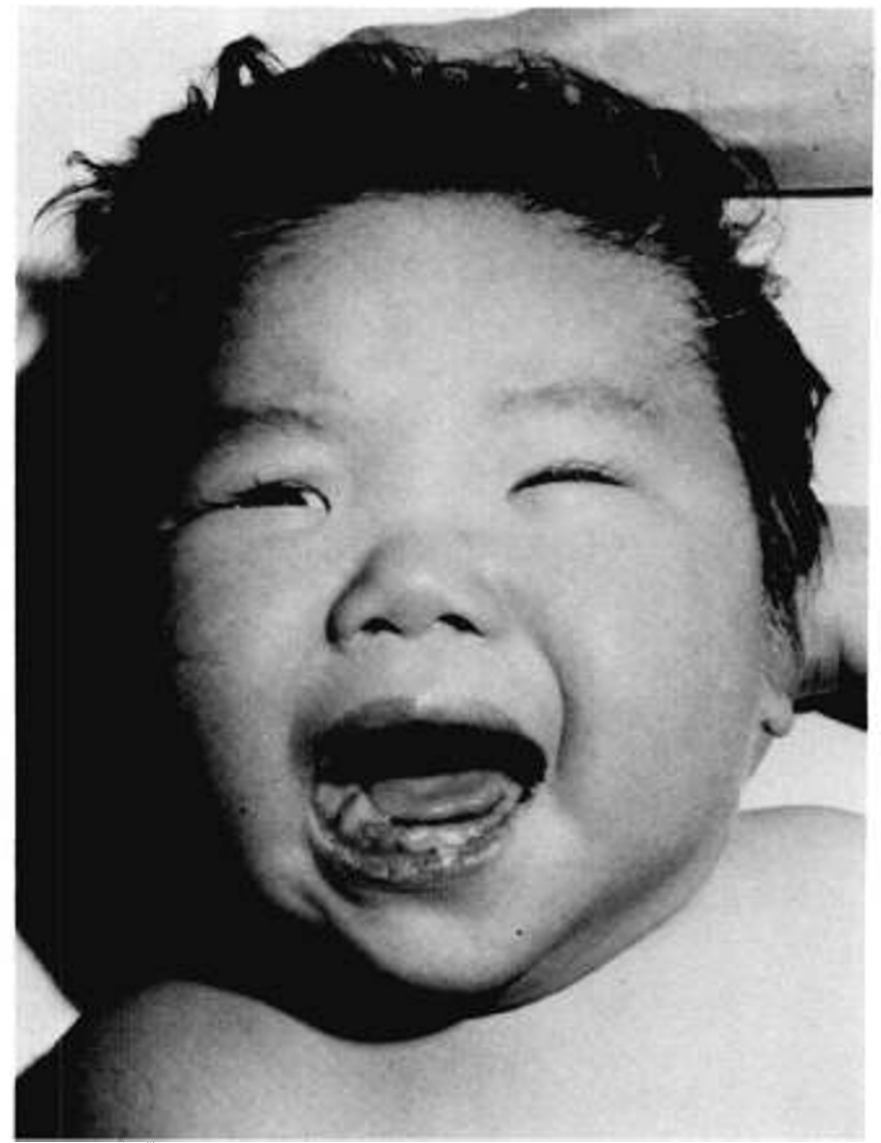

Fig. 1. A patient with kinky hair disease at the age of $2 \mathrm{yr}$, showing hypertrophic gingiva.

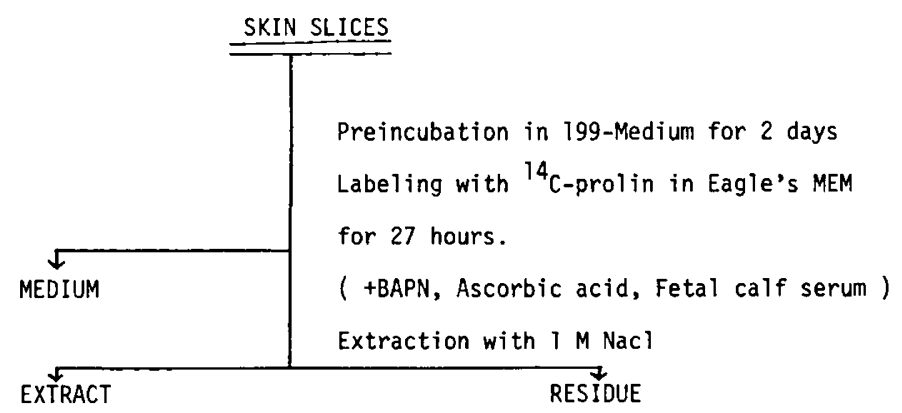

Fig. 2. A schematic representation of biochemical analysis of skin collagen

in Epon 812. Some specimens were fixed in two parts cacodylatebuffered glutaraldehyde and one part ruthenium red at $4^{\circ} \mathrm{C}$ for 2 $\mathrm{hr}$, and postfixed in equal parts $2 \%$ osmium tetroxide in cacodylate buffer and ruthenium red for $3 \mathrm{hr}$. Thin sections were stained with uranyl acetate and lead citrate, and sections prestained with ruthenium red were stained with uranyl acetate. Observations were carried out in a JEOL JEM-100B electron microscope.

\section{RESULTS}

\section{LABORATORY FINDINGS}

Blood cell counts and blood chemistry determinations including the levels of sodium, potassium, calcium, phosphorus, SGOT, SGPT, LDH, blood urea nitrogen, glucose, serum protein, and immunoglobulin, were normal. Serum protein electrophoresis and thyroid function tests were showed normal results. The serum copper level was $9.6 \mu \mathrm{g} / \mathrm{dl}$; serum zinc, $121.0 \mu \mathrm{g} / \mathrm{dl}$; and cerulo- plasmin, $3.6 \mathrm{mg} / \mathrm{dl}$. Microscopic observation of the hair revealed twisting of the hair shaft (pili torti) and bead-like enlargement (monilethrix).

\section{RADIOLOGIC FINDINGS}

At the age of 5 months, a cerebral angiography revealed increased tortuosity of intracranial vessels (Fig. 3) and an aortgram also showed excessive tortuous visceral and renal vessels (Fig. 4). At $3 \mathrm{yr}$ of age, a cystogram showed an enlarged and trabeculated urinary bladder (Fig. 5). On X-ray of the extremities, it was discovered that the metaphysis of the ulna and the radius widened with lateral spurs.

\section{NEUROPHYSIOLOGIC FINDINGS}

The EEG showed multifocal spikes with high amplitude, irregular slow waves at the age of 5 months, episodic hypsarrhythmia at 10 months. The background activities gradually decreased in amplitude, at which time, multifocal spikes were seen. The VER showed low amplitude at the age of 9 months, which disappeared by the age of 1 yr. The AER revealed low amplitude at 9 and 23 months, which disappeared at 33 months of age.

\section{BIOSYNTHETIC ACTIVITY FOR COLLAGEN AND HISTOCHEMISTRY OF SKIN FIBROBLASTS}

Hydroxyproline, which is found almost exclusively in collagen, is synthesized by hydroxylation of proline after this imino acid has been incorporated into peptide linkage (2). Consequently, $\left[{ }^{14} \mathrm{C}\right]-$ or $\left[{ }^{3} \mathrm{H}\right]$ proline can be used as a precursor in studies on the molecular aspects of collagen biosynthesis.

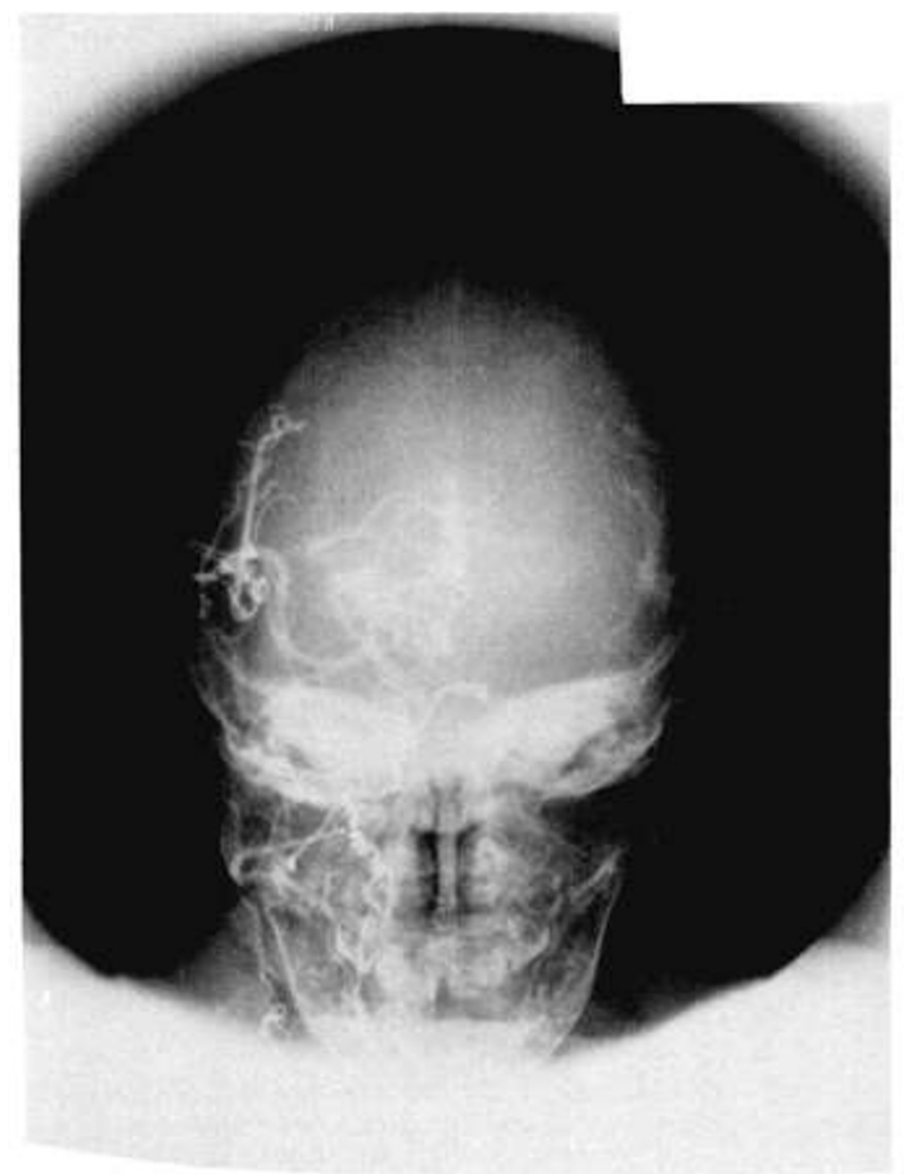

Fig. 3. Cerebral angiogram showing increased tortuosity of intracranial vessels. 


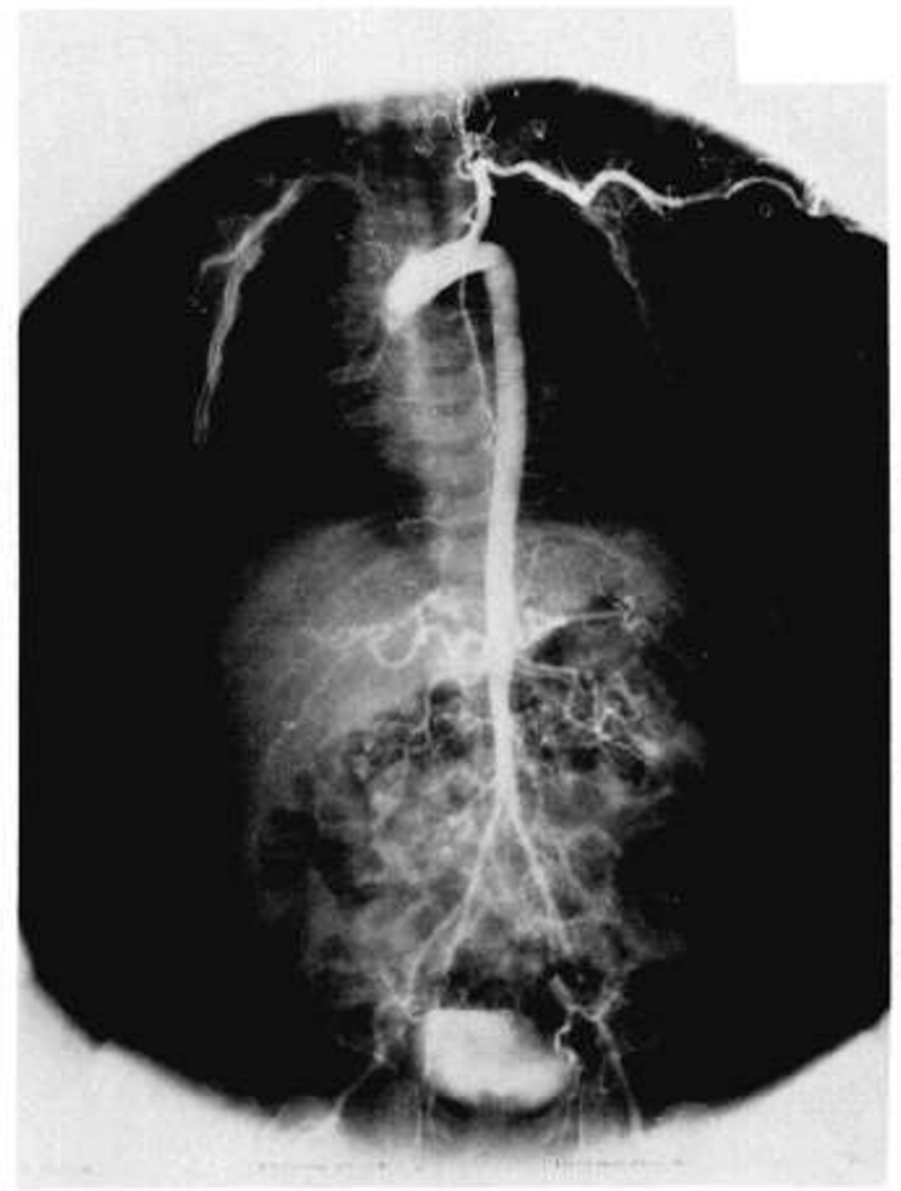

Fig. 4. Aortogram showing excessively tortuous visceral and renal vessels.

Total radioactivity $\left(\left[{ }^{14} \mathrm{C}\right]\right.$ hydroxyproline plus $\left[{ }^{14} \mathrm{C}\right]$ proline), which represents the synthetic activity for collagenous and noncollagenous protein, incorporated into the affected skin was about $70 \%$ of that of the control skin, while the radioactivity of $\left[{ }^{14} \mathrm{C}\right]$ hydroxyproline, representing the synthetic activity for collagen, was approximately $50 \%$ (Table 1). The fibroblasts were stained negatively with alcian blue and faintly positive with PAS. Coarse granules stained positively with fast-green FCF were observed in the cystoplasm by the Masson's trichrome method.

\section{ULTRASTRUCTURAL FINDINGS OF CARTILAGE}

The chondrocytes showed fibroblasts appearing feature, poorly developed organelles, deformed nucleus, and small glycogen accumulation (Fig. 6). The most striking feature in the extracellular matrix of the cartilage was the size of the irregular collagen fibrils. Some fibrils were especially huge in width and were spaced far apart (Fig. 7). They consisted of fibrils which measured 1500 $1800 \AA$ and $200-300 \AA$ wide. Fibrils, $300-600 \AA$ wide and common in the cartilage matrix, were rather small in number. Ruthenium red staining granules presumed to be proteoglycans in the cartilage matrix were relatively small in size and few in number and showed high electron density (Fig. 8).

\section{DISCUSSION}

Collagen and elastin are the major structural proteins of the body. They are known to undergo several biosynthetic steps, and crosslinking is an essential feature to reach their mature form. It has been reported that the copper ion is a cofactor of lysyloxidase of collagen and elastin, and its deficiency produces a reduced number of crosslinkings.

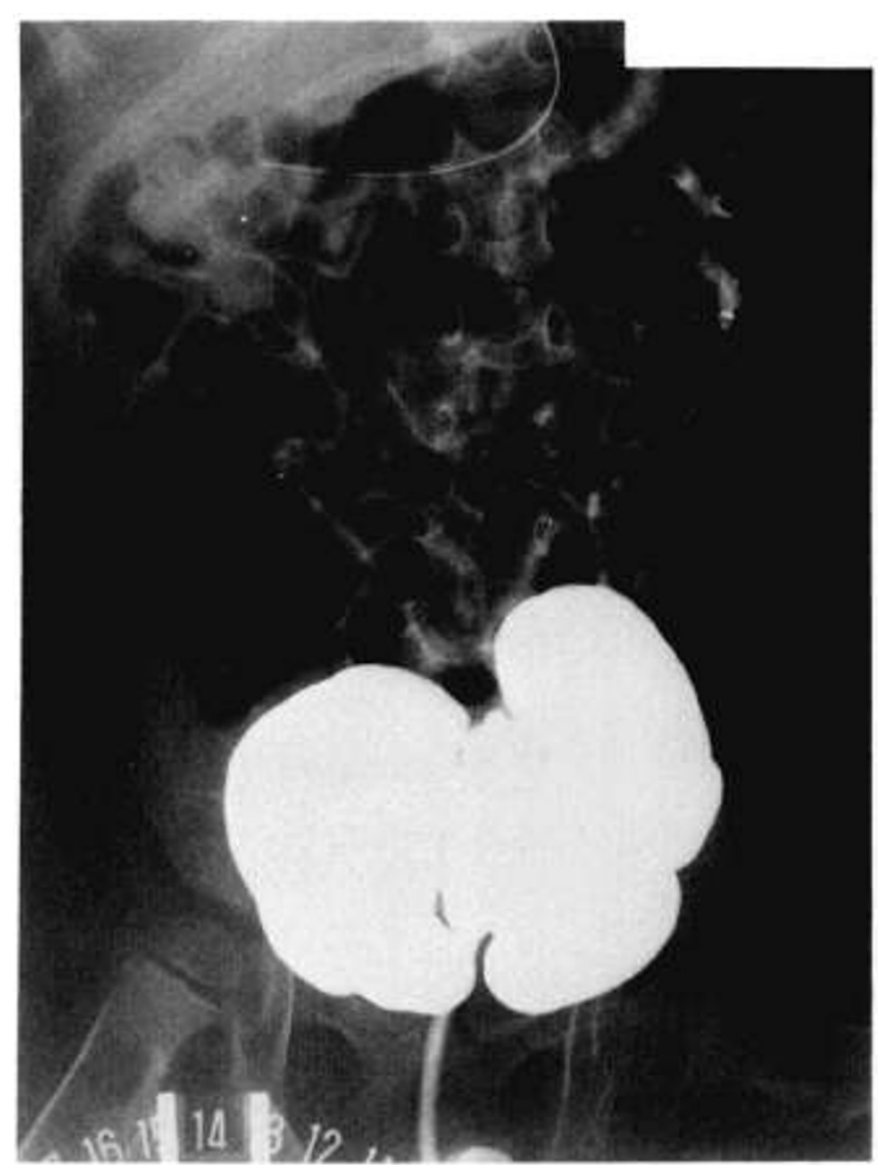

Fig. 5. Cystogram showing an enlarged and trabeculated urinary bladder.

Table 1. Radioactivity of $\left[{ }^{14} \mathrm{C}\right]$ proline-labeled materials in the fractions prepared from the skin segments ${ }^{a}$

\begin{tabular}{lrrrr}
\hline & Medium & Extract & Residue & Total \\
\hline Kinky hair disease & & & & \\
Total radioactivity & 1900 & 4460 & 1240 & $7600(67 \%)$ \\
{$\left[{ }^{14} \mathrm{C}\right]$ hydroxyproline } & 135 & 1081 & 184 & $1400(54 \%)$ \\
& & & & \\
Control & & & & \\
$\quad$ Total radioactivity & 2780 & 7650 & 887 & $11300(100 \%)$ \\
{$\left[{ }^{14} \mathrm{C}\right]$ hydroxyproline } & 163 & 2174 & 250 & $2590(100 \%)$ \\
\hline
\end{tabular}

${ }^{a}$ All the values were expressed as $\mathrm{cpm} / \mathrm{mg}$ wet wt of the original skin segments.

This biochemical study demonstrates that the synthetic activity for proteins was reduced in the skin of kinky hair disease, especially the biosynthetic activity for collagen. The results indicate that the metabolic disorder of copper may play a role in the reduced biosynthesis of collagen in the patient. In tissue cultures, fast-green FCF staining coarse granules were found in the cytoplasm of skin fibroblasts from the patient. There is a possibility that these granules may be a precursor material of collagen, accumulated in the cells due to a metabolic disorder. The appearance of huge collagen fibrils in the cartilage matrix may be related to the decreased number of proteoglycan granules which are considered to play a role in fiber formation $(6,9)$. It may indicate that there is an intimate interrelationship between collagen and proteoglycan, although the details of the interrelationship are not yet fully known.

Although twisted arteries, hypertrophic gingiva, trabeculated bladder, and other peculiar findings associated with kinky hair 


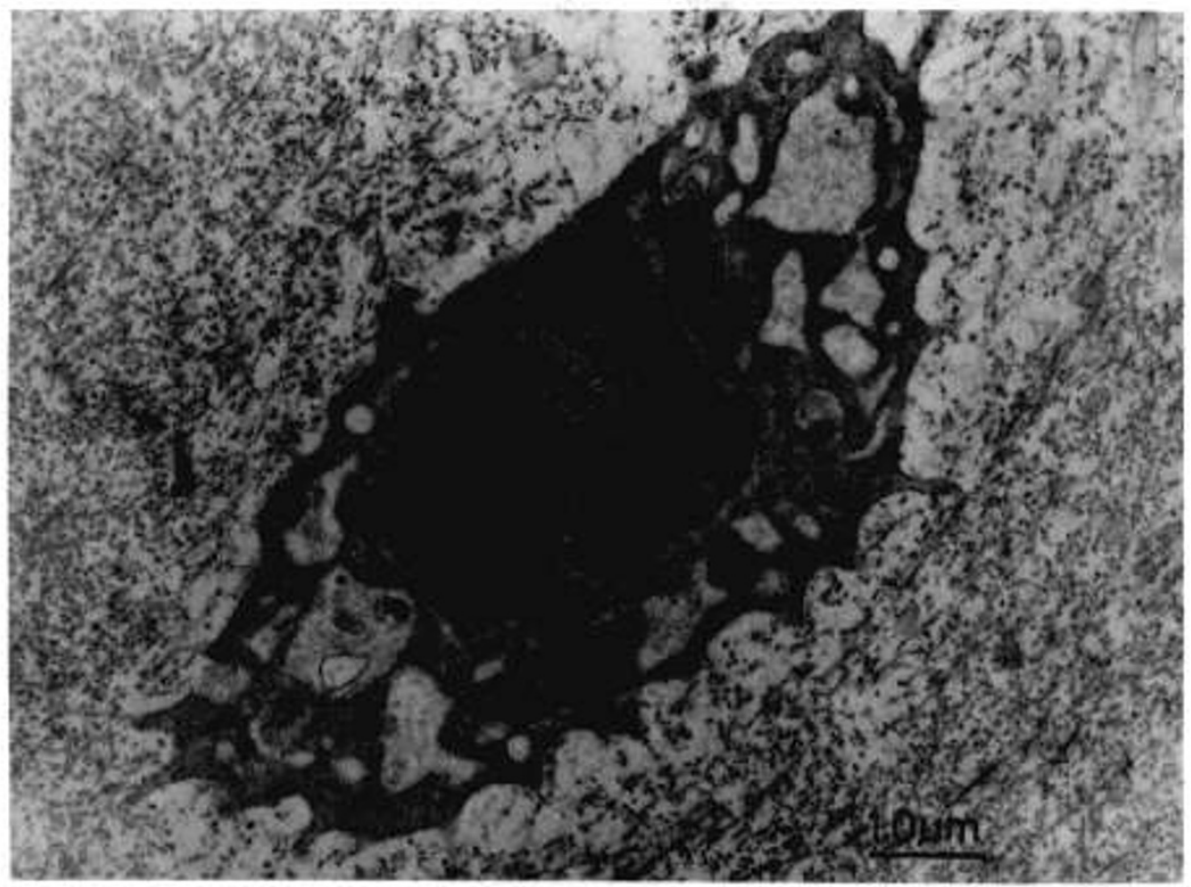

Fig. 6. Electron micrograph of chondrocyte from the iliac cartilage showing poor development of organelles and dilatation of coarse endoplasmic reticulum.

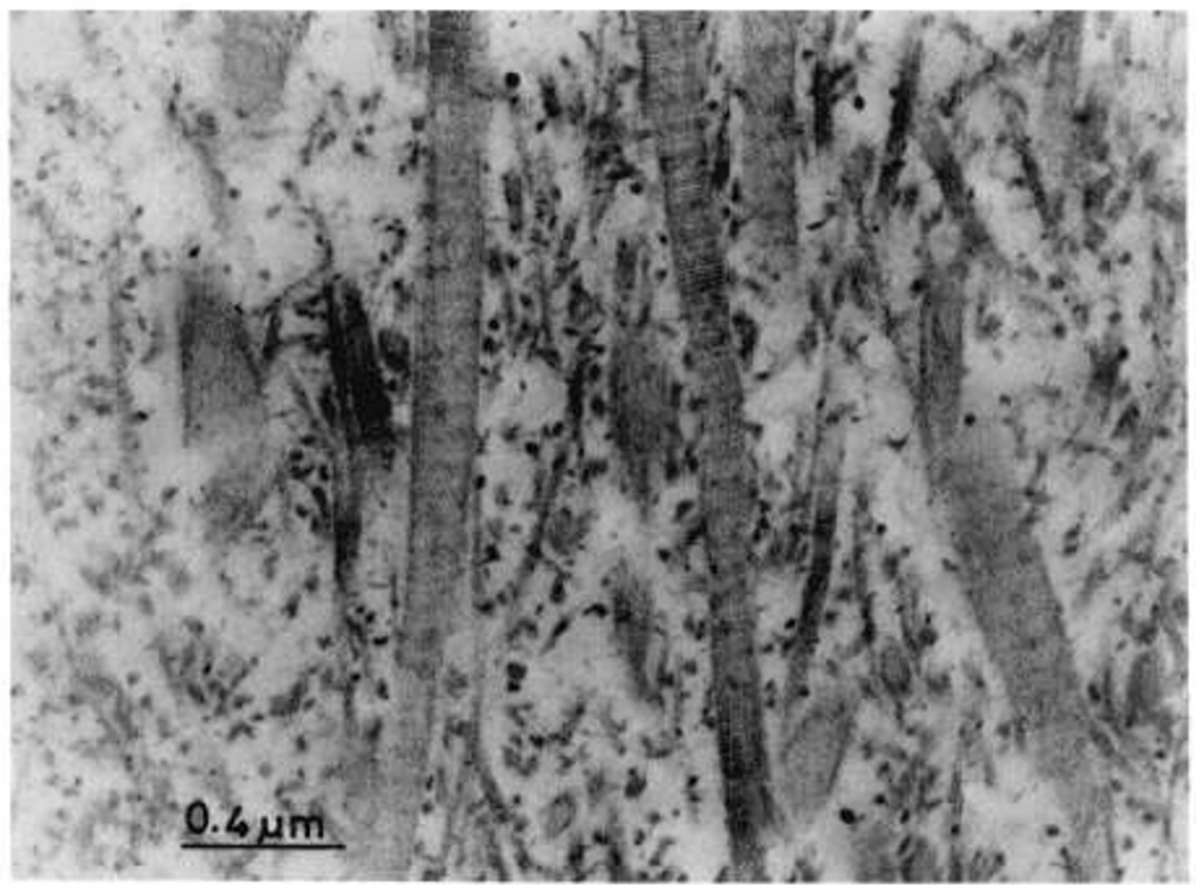

Fig. 7. Electron micrograph of iliac cartilage matrix showing huge or thin collagen fibrils.

disease may partially be the result of an abnormal metabolism of collagen and elastin due to defective intestinal absorption of copper (3), it cannot fully explain the cause of the disease.

Because kinky hair was already observed in the newborn infant and the administration of copper was not very effective $(4,5)$ in the treatment of the disease, the basic defect may be regarded as a broader metabolic disorder of cells affecting the physical prop- erties of various tissues. Such a metabolic disorder intensively affects the growing body or tissues where synthesis is rapid, and in kinky hair disease, progressive neurodegenerative symptoms usually start early in life after a brief normal development. A marked morphologic change of the urinary bladder in our patient may be one example showing the progressive and degenerative tendency of the disease. 


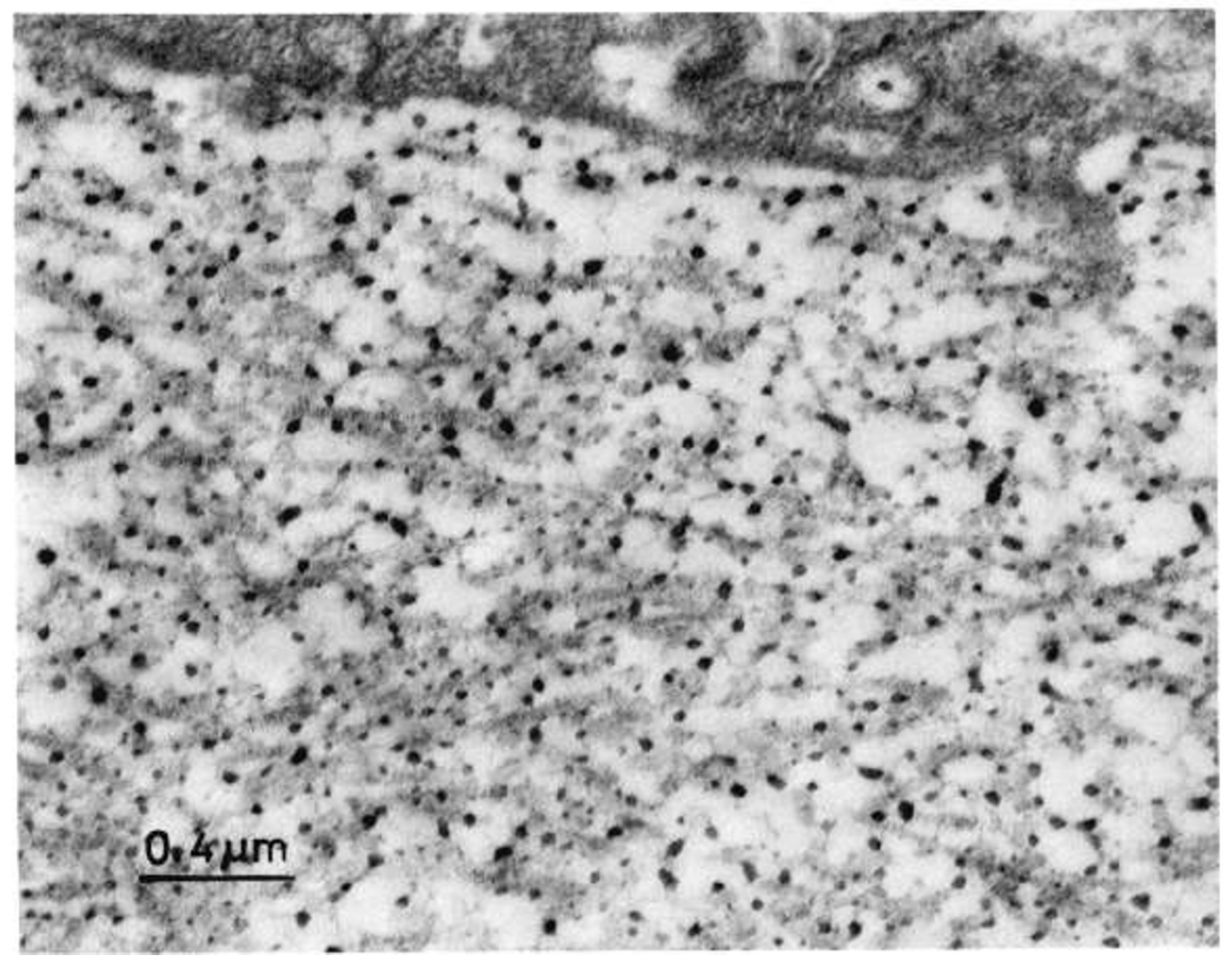

Fig. 8. Electron micrograph of iliac cartilage matrix showing ruthenium red staining coarse granules presumed to be proteoglycans. A part of chondrocyte is shown on the top.

\section{REFERENCES AND NOTES}

1. Bailey, A. J., Robins, S. P., and Balian, G.: Biological significance of the intermolecular crosslinks of collagen. Nature, 251: 105 (1974).

2. Bornstein. P. The biosynthesis of collagen. Ann. Rev. Biochem., 43: 567 (1974).

3. Danks, D. M. Campbell. P. E.. Stevens, B. J., Mayne, V., and Cartwright. E. Menkes's kinky hair syndrome. An inherited defect in copper absorption with widespread effect. Pediatrics, 50: 188 (1972)

4 Garnica, A. D. Frias, J. L., Easley, J. F., and Rennert. O. M.: Menkes's kinky hair disease. A defect in Metallothionein metabolism? Clinical cytogenetics and genetics. Birth defects, Original article series. The National Foundation. March of Dimes. Vol 10, 8: 149 (1974).

5. Grover. W. D., and Scrutton, M. C.: Copper infusion therapy in trichopoliodystrophy. J. Pediatr., 86: 216 (1975).
6. Hough, A. J., Mottram, F. C., and Sokoloff. I.: The collagenous nature of amianthoid degeneration of human costal cartilage. Amer. J. Pathol., 73: 201 (1973).

7. Juva. K.. and Prockop, D. J.: Modified procedure for the assay of $\mathrm{H}^{3}$ - or $\mathrm{C}^{14}$ labeled hydroxyproline. Anal. Biochem., 15: 77 (1966).

8. Menkes, J. H., Alter, M.. Steigleder, G. K., Weakley, D. R.. and Sung, J. H.: A sex-linked recessive disorder with retardation of growth, peculiar hair, and focal cerebral and cerebellar degeneration. Pediatrics, 29: 764 (1962).

9. Seegmiller, R., and Sheldon, H.: A new chondrodystrophic mutantin mice. J. Cell. Biol., 48: 580 (1971).

10. Siegel, R. C.. Pinnel. S. R., and Martin, G. R.: Cross-linking of collagen and elastin. Properties of lysyl oxidase. Biochemistry, 9: 4486 (1970).

11. Received for publication January 10, 1979.

12. Accepted for publication June 1, 1979. 